\title{
Delineation of Khuff Reservoir in Kra Al Maru Area of Kuwait Using Seismic Inversion and Lithology Modeling: A Case Study
}

\author{
Hameed Shereef (Kuwait Oil Company, mshereef@kockw.com), Osman Al-Khaled (Kuwait Oil \\ Company, <OKhaled@kockw.com>), Yousef Al-Zuabi and Tasneem Al-Rashid (Kuwait Oil Company)
}

A seismic reservoir characterization study was carried out over the Kra Al Maru structural trend in Kuwait to model the lithology of the Permian-Triassic Khuff reservoir. The dominant lithologies of the Khuff Formation are dolomites and dolomitic limestone with thin inter-beds of anhydrite and shale. The Khuff Formation has been divided into three units based on the lithological characters observed from one well. All three units contain dolomites, limestone, anhydrite and shale. The seismic data used was processed in 2005 with 25 meter bin spacing. Only one well was available for this study with the required $\log$ suite. The technique used was the Constraint Sparse Spike Inversion (CSSI) to produce the Acoustic Impedance (AI) volume. The principle objective of seismic inversion is to transform seismic reflection data into a quantitative Khuff rock property. A relationship between the acoustic impedance (AI) log and porosity log was established using the available well data to transform the AI volume to lithology volume.

\section{Methodology}

In this study, one available well was considered for well-to-seismic correlation. At the well location an acoustic impedance log was generated using the sonic and density logs. As part of the well-to-seismic calibration process a synthetic Ricker wavelet was generated and scaled to seismic amplitudes. The synthetic seismogram was computed using the synthetic Ricker wavelet and the acoustic impedance log. The match between the synthetic seismogram and the seismic trace was reasonable from the Jilh Dolomite to the bottom of Khuff, which allowed a reasonable estimation of the wavelet. A 3-D acoustic impedance model was built using an interpolation technique that is guided by the interpreted horizons and the stratigraphic framework provided by the interpreters. This model was used to provide the lowfrequency component for the seismic inversion. The CSSI technique was used to generate the relative acoustic impedance volume with band-pass frequency of 10-40 Hz. Figure 1 shows the relative acoustic impedance and absolute impedance volumes. The relative acoustic impedance 3-D model was then merged with the low-frequency component of the well acoustic impedance 3-D model to produce the final absolute acoustic impedance (Full bandwidth). Quality control steps were carried out to check the validity of seismic inversion volume. The relationship between AI and porosity was established from the well logs through cross plots for the reservoir layer from top to base of the Khuff Formation. This relationship was applied on the final absolute AI volume to transform into a lithology volume.

\section{Results and Conclusions}

This study identified a low-impedance layer in the final absolute AI volume within the Khuff. It also showed a high porosity layer in the lithology volume within the Khuff, which may be related to the shale content. The high acoustic impedance values are related to dolomite content but no clear evidence of prospective matrix porosity observed. The log characters also indicate poor reservoir potential. The study has allowed reconsidering the future drilling plan targeting the Khuff Formation in Kra Al Maru and has helped the geophysicists to reinterpret the deep horizons with a good level of confidence by using the relative AI volume (seismic band pass inversion). 


\section{EAGE}

\section{Acknowledgements}

The authors express their thanks to the Management of Kuwait Oil Company (K.S.C.) and the Ministry of Oil, the State of Kuwait, for permission to publish this paper.

\section{References}

Bou-Rabee., F.A.1986. The geology and geophysics of Kuwait. PhD dissertation, University of South Carolina, $150 \mathrm{p}$.

Soroka, W. and L.M. Shoemaker 2003. Impedance inversion in a structurally complex carbonate environment, Abu Dhabi UAE, SEG, Dallas.

Hameed, M. and B. Al Ajmi 2003. KOC, Delineation of carbonate reservoirs in Raudhatain and Sabriyah fields of North Kuwait, case study, EAGE/SPE, Abu Dhabi, 2009.

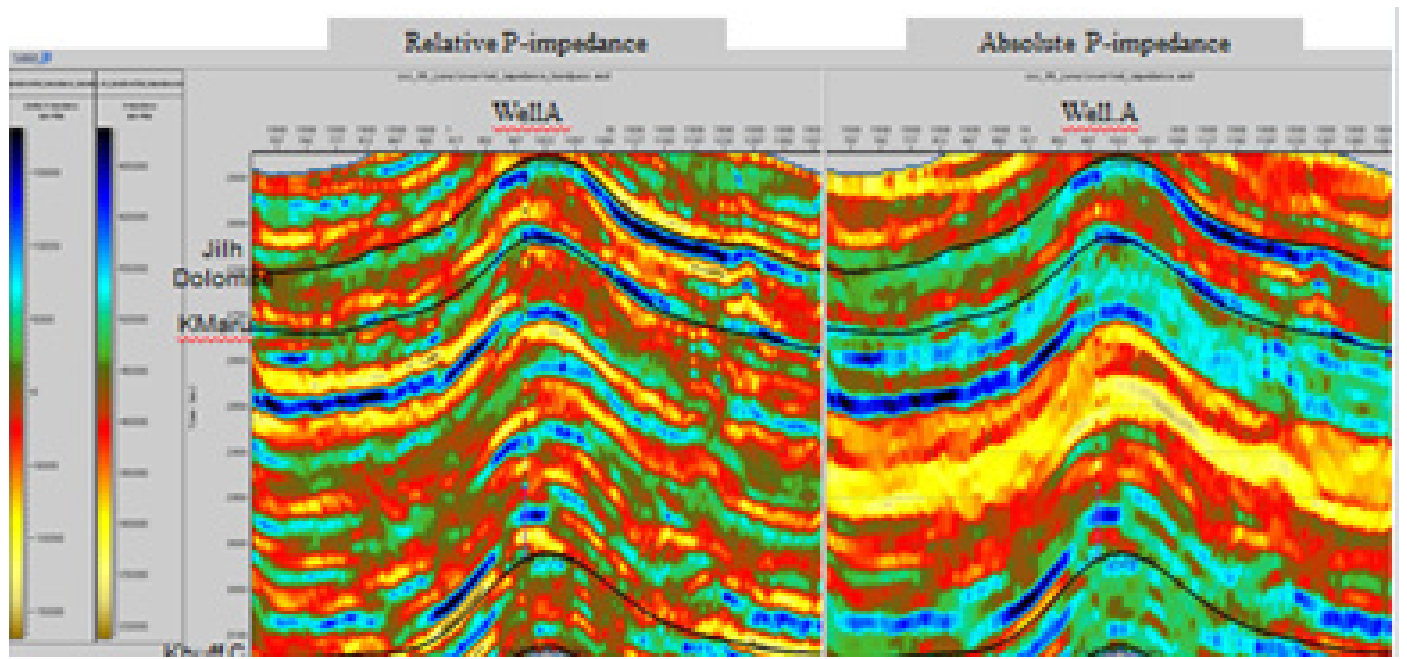

Figure 1: Relative (left) and absolute (right) acoustic impedance. 